\title{
24-Hour Serial Spirometric Assessment of Once-Daily Fluticasone Furoate/Umeclidinium/Vilanterol Versus Twice-Daily Budesonide/Formoterol in Patients with COPD: Analysis of the FULFIL Study
}

\author{
David A. Lipson · Ruby Birk • Noushin Brealey • Chang-Qing Zhu
}

Received: July 7, 2020 / Accepted: September 3, 2020 / Published online: October 3, 2020

(C) The Author(s) 2020

\begin{abstract}
Introduction: Few studies have utilized 24-h serial spirometry to compare the effects of inhaled chronic obstructive pulmonary disease (COPD) therapies on lung function. The FULFIL study previously reported significant lung function improvements with once-daily singleinhaler fluticasone furoate/umeclidinium/ vilanterol (FF/UMEC/VI) versus twice-daily single-inhaler budesonide/formoterol (BUD/FOR) in patients with symptomatic COPD at risk of exacerbations.

Methods: This prespecified analysis evaluated 24-h serial spirometry data from a subgroup of 406 patients in FULFIL. BUD/FOR twice-daily dosing was maintained during 24-h spirometry. A post hoc analysis evaluated serial forced expiratory volume in $1 \mathrm{~s}\left(\mathrm{FEV}_{1}\right)$ at day 1 and
\end{abstract}

D. A. Lipson $(\bowtie)$

GSK, 1250 S Collegeville Rd, Collegeville, PA 19426,

USA

e-mail: david.a.lipson@gsk.com

D. A. Lipson

Perelman School of Medicine, University of

Pennsylvania, 3400 Civic Center Blvd, Philadelphia,

PA 19104, USA

R. Birk · N. Brealey · C.-Q. Zhu

GSK, Stockley Park West, Iron Bridge Rd N, West

Drayton, Uxbridge UB11 1BT, UK week 24 by disease severity at screening $\left(\mathrm{FEV}_{1}\right.$ $<50 \%$ predicted and no moderate or severe exacerbation in prior year, $\mathrm{FEV}_{1}<50 \%$ predicted and $\geq 1$ moderate or severe exacerbation in prior year, and $\mathrm{FEV}_{1} \geq 50 \%$ and $<80 \%$ predicted and $\geq 2$ moderate or $\geq 1$ severe exacerbations in prior year).

Results: Odds of achieving $\mathrm{a} \geq 100-\mathrm{mL}$ increase from baseline in $\mathrm{FEV}_{1}$ within the first $6 \mathrm{~h}$ post dose on day 1 were significantly greater with FF/UMEC/VI than BUD/FOR [odds ratio 2.79 (95\% confidence interval 1.56-4.98); $p<0.001$ ]. $\mathrm{FF} / \mathrm{UMEC} / \mathrm{VI}$ led to greater improvements in weighted mean $\mathrm{FEV}_{1}$ over $0-6,0-12,0-24$, and $12-24 \mathrm{~h}$ on day 1 and at week 24 , with the greatest between-group differences at week 24 (range 196-210 mL; all $p<0.001$ ). Significant between-treatment differences in $\mathrm{FEV}_{1}$ and forced vital capacity (FVC) in favor of FF/UMEC/VI versus BUD/FOR were seen at all time points at week $24\left(\mathrm{FEV}_{1}\right.$ range $156-231 \mathrm{~mL}$, all $p<0.001 ;$ FVC range $139-309 \mathrm{~mL}$, all $p \leq 0.002$ ). Serial $\mathrm{FEV}_{1}$ results were consistent irrespective of disease severity at screening.

Conclusion: These findings further demonstrate sustained lung function benefits with once-daily FF/UMEC/VI single-inhaler triple therapy in patients with symptomatic COPD at risk of exacerbations across a range of disease severities. 
Keywords: Chronic obstructive pulmonary disease; Lung function; Single-inhaler triple therapy; Long-acting $\beta_{2}$-agonist; Long-acting muscarinic antagonist; Inhaled corticosteroid; Serial $\mathrm{FEV}_{1}$

\section{Key Summary Points}

\section{Why carry out this study?}

Few studies utilize 24-h serial spirometry to compare the effects of inhaled chronic obstructive pulmonary disease (COPD) therapies on lung function.

This prespecified analysis of the FULFIL trial evaluated 24-h serial spirometry in a subgroup of 406 symptomatic patients with COPD at risk of exacerbations treated with once-daily fluticasone furoate/ umeclidinium/vilanterol (FF/UMEC/VI) or twice-daily budesonide/formoterol (BUD/FOR).

\section{What was learned from the study?}

At week 24, treatment with FF/UMEC/VI increased lung function compared with BUD/FOR, as demonstrated by forced expiratory volume in $1 \mathrm{~s}\left(\mathrm{FEV}_{1}\right)$ increases from baseline of 160 to $339 \mathrm{~mL}$ and -32 to $140 \mathrm{~mL}$, respectively, across the $24-\mathrm{h}$ period, with statistically significant treatment differences at every time point favoring FF/UMEC/VI (range 156-231 mL; $p<0.001)$.

Treatment with once-daily FF/UMEC/VI showed sustained clinically relevant improvements in lung function throughout the 24-h dosing period compared with twice-daily BUD/FOR, starting from day 1 . In a post hoc analysis, FF/UMEC/VI provided lung function benefits compared with twice-daily BUD/FOR in patients with varying degrees of COPD severity, starting from day 1 and sustained through to week 24 .
These data further support the lung function benefits of once-daily FF/UMEC/VI single-inhaler triple therapy in symptomatic patients with COPD at risk of exacerbations.

\section{DIGITAL FEATURES}

This article is published with digital features to facilitate understanding of the article. To view digital features for this article go to https://doi. org/10.6084/m9.figshare.12906452.

\section{INTRODUCTION}

Chronic obstructive pulmonary disease (COPD) is a progressive disease characterized by persistent airflow limitation and is a leading contributor to global morbidity and mortality [1]. Inhaled triple therapy [inhaled corticosteroids (ICS)/long-acting $\beta_{2}$-agonists (LABA)/long-acting muscarinic antagonists (LAMA)] is recommended in the Global Initiative for Chronic Obstructive Lung Disease (GOLD) strategy document for patients with COPD who have persistent symptoms and are at risk of exacerbations despite receiving dual ICS/LABA or LAMA/LABA therapy [1]. This escalation to triple therapy in patients on COPD maintenance dual therapy is frequently seen in clinical practice $[2,3]$.

LABAs and LAMAs exert their bronchodilatory effects through different mechanisms of action, relaxing the smooth muscles or inhibiting pulmonary constriction, and this combination helps maximize bronchodilation in patients with COPD [4]. Indeed, LAMA/LABA combinations have demonstrated significantly greater improvements in lung function compared with monotherapy in COPD [4].

The phase III Lung Function and Quality of Life Assessment in COPD with Closed Triple Therapy (FULFIL) trial was the first to compare once-daily single-inhaler triple therapy with twice-daily dual therapy in patients with 
symptomatic COPD at risk of exacerbations [5]. The primary analysis of FULFIL demonstrated statistically significant and clinically meaningful improvements in the co-primary endpoints of change from baseline in trough forced expiratory volume in $1 \mathrm{~s}\left(\mathrm{FEV}_{1}\right)$ and St George's Respiratory Questionnaire (SGRQ) total score at week 24 with FF/UMEC/VI 100/62.5/25 $\mu \mathrm{g}$ versus budesonide/formoterol (BUD/FOR) $400 / 12 \mu \mathrm{g}$ [5].

Few studies have utilized 24-h spirometric assessments to evaluate treatment differences on lung function across the full dosing interval [6]. Here, we report results from a prespecified analysis of 24-h serial spirometry in a subgroup of patients in FULFIL. In addition, a post hoc analysis evaluated serial spirometry by disease severity at screening.

\section{METHODS}

\section{Study Design}

The design of FULFIL, a phase III, randomized, double-blind, double-dummy, parallel-group, multicenter study (GSK study CTT116853; NCT02345161) has been described in detail elsewhere [5]. Briefly, patients were randomized to receive 24 weeks of treatment with oncedaily FF/UMEC/VI $(100 / 62.5 / 25 \mu \mathrm{g})$ using the ELLIPTA inhaler and twice-daily placebo using the Turbuhaler, or twice-daily BUD/FOR (400/ $12 \mu \mathrm{g})$ via the Turbuhaler and once-daily placebo with the ELLIPTA inhaler [5]. To minimize the impact of different dosing regimens, all patients took one inhalation from the ELLIPTA inhaler in the morning and two inhalations (one in the morning and one in the evening) from the Turbuhaler.

The study comprised a 2-week run-in period, during which medications at screening were unchanged, followed by a 24-week treatment period, and a further extension period up to 52 weeks for a subset of patients. To minimize data loss, patients who permanently discontinued study treatment, but did not withdraw consent, were not required to withdraw from the study and certain efficacy and safety assessments were continued. A subgroup of randomized patients from selected centers consented to participate in serial 24-h spirometric assessments (referred to as the serial spirometry subgroup) at randomization on day 1 and at week 24, with measurements taken at 30 and $5 \mathrm{~min}$ pre morning dose, and 15, $30 \mathrm{~min}$, and $1,3,6,12,15,21,23$, and $24 \mathrm{~h}$ post morning dose. Baseline $\mathrm{FEV}_{1}$ measurements were taken at the screening visit, and trough $\mathrm{FEV}_{1}$ measurements were taken as close to $24 \mathrm{~h}$ as possible after the previous morning dose for patients randomized to FF/UMEC/VI, or as close to $12 \mathrm{~h}$ as possible after the last evening dose for patients randomized to BUD/FOR, and prior to the next dose. Study-supplied salbutamol had to be withheld for at least $4 \mathrm{~h}$ prior to spirometry testing. All spirometry assessments were conducted using MasterScopes spirometers supplied by ERT (Estenfeld, Germany), which met or exceeded the minimal performance recommendations of the American Thoracic Society/ European Respiratory Society (ATS/ERS) Task Force for Standardization of Lung Function Testing [7]. For $\mathrm{FEV}_{1}$ and forced vital capacity (FVC) determinations, at least three (and no more than eight) acceptable spirometry efforts were obtained. The largest $\mathrm{FEV}_{1}$ and FVC measurements from the three acceptable efforts were recorded, even if they did not come from the same effort.

This study was conducted in accordance with the Declaration of Helsinki and Good Clinical Practice guidelines. Individual institutional review boards at each clinical site approved the protocol. Written consent was obtained from the subjects or their surrogates as required by the institutional review boards.

\section{Study Population}

Patients were $\geq 40$ years of age with a COPD Assessment Test (CAT) score $\geq 10$ and had a post-bronchodilator $\mathrm{FEV}_{1}<50 \%$ of predicted normal values, or a post-bronchodilator $\mathrm{FEV}_{1}$ $<80 \%$ of predicted normal values and $\geq 2$ moderate exacerbations or $\geq 1$ severe exacerbation in the past year. Moderate exacerbations were defined as those requiring treatment with oral/systemic corticosteroids and/or antibiotics 
(not involving hospitalization), while severe exacerbations were defined as those requiring hospitalization.

Patients were required to be already receiving daily maintenance therapy for COPD for at least 3 months prior to study entry. Patients were excluded if they had a current diagnosis of asthma, or pneumonia, or a severe exacerbation that had not resolved within 14 days of screening.

\section{Study Endpoints}

Prespecified efficacy endpoints evaluated in the serial spirometry subgroup on day 1 and week 24 included time to onset of bronchodilation (increase of $\geq 100 \mathrm{~mL}$ over baseline in $\mathrm{FEV}_{1}$ ) 0-6 $\mathrm{h}$ post dose on day 1 ; serial $\mathrm{FEV}_{1}$ on day 1 and week 24; weighted mean $\mathrm{FEV}_{1}$ over $0-6,0-12,0-24$, and $12-24 \mathrm{~h}$ on day 1 and week 24; peak $\mathrm{FEV}_{1}$ on day 1 and week 24; and serial FVC on day 1 and week 24 . A post hoc analysis evaluated serial $\mathrm{FEV}_{1}$ at day 1 and week 24 by disease severity at screening, defined according to airflow obstruction and exacerbation history: $\mathrm{FEV}_{1}<50 \%$ predicted and no moderate or severe exacerbation in the prior year, $\mathrm{FEV}_{1}<50 \%$ predicted and $\geq 1$ moderate or severe exacerbation in the prior year, and $\mathrm{FEV}_{1} \geq 50 \%$ and $<80 \%$ predicted and $\geq 2$ moderate or $\geq 1$ severe exacerbations in the prior year. Percentage predicted values were calculated using the ERS Global Lung Function Initiative reference equations [8]. Safety was previously assessed in the intent-to-treat (ITT) population.

\section{Statistical Analyses}

Time to onset of bronchodilation on day 1 was analyzed using a Cox proportional hazards model with covariates of treatment group, smoking status, geographical region, and baseline $\mathrm{FEV}_{1}$, and estimated from the Kaplan-Meier survivor function. The proportion of patients achieving an increase from baseline in $\mathrm{FEV}_{1}$ of $\geq 100 \mathrm{~mL}$ during $0-6 \mathrm{~h}$ post dose on day 1 was analyzed using a generalized linear mixed model with a logit link function and covariates of treatment group, smoking status (screening), geographic region, visit, baseline value, and baseline-by-visit and treatment-by-visit interactions. Serial spirometry measures of $\mathrm{FEV}_{1}$ and FVC at each time point during $0-24 \mathrm{~h}$ post dose were analyzed using a repeated measures model with covariates of treatment group, smoking status (screening), geographic region, time point, baseline, and baseline-by-time point and treatment-by-time point interactions. Weighted mean $\mathrm{FEV}_{1}$ over $0-6,0-12,0-24$, and $12-24 \mathrm{~h}$ post dose, and peak $\mathrm{FEV}_{1}$ on day 1 and week 24 were analyzed using repeated measures models with covariates of treatment group, smoking status (screening), geographical region, visit, baseline value, and baseline-by-visit and treatment-by-visit interactions. The post hoc analysis of serial $\mathrm{FEV}_{1}$ by disease severity at screening was performed using repeated measures models with covariates of treatment group, smoking status (screening), geographic region, time point, baseline, and baseline-by-time point and treatment-by-time point interactions.

\section{RESULTS}

\section{Study Population}

Among the ITT population $(N=1810), 406$ patients (FF/UMEC/VI: $N=203 ; \quad$ BUD/FOR: $N=203$ ) had serial 24-h spirometry assessments available and were included in the serial spirometry subgroup. Baseline demographic and disease characteristics in this subgroup were well balanced between treatment arms and similar to those of the overall ITT population [5] (Table 1). The majority of patients were male and COPD severity at screening was similar between ITT and serial spirometry populations, with approximately two-thirds of patients having a GOLD grade of $3 / 4$. The serial spirometry subgroup had a slightly greater proportion of patients with $\geq 2$ moderate or $\geq 1$ severe exacerbation in the prior year and slightly higher pre-bronchodilator lung function measurements (Table 1). 
Table 1 Baseline demographics and disease characteristics for the serial spirometry population

\begin{tabular}{|c|c|c|c|c|}
\hline & \multicolumn{2}{|c|}{ Serial spirometry population } & \multicolumn{2}{|c|}{ Overall ITT population } \\
\hline & $\begin{array}{l}\text { FF/UMEC/VI } \\
100 / 62.5 / 25 \mu \mathrm{g} \\
(N=203)\end{array}$ & $\begin{array}{l}\text { BUD/FOR } \\
400 / 12 \mu \mathrm{g} \\
(N=203)\end{array}$ & $\begin{array}{l}\text { FF/UMEC/VI } \\
100 / 62.5 / 25 \mu \mathrm{g} \\
(N=911)\end{array}$ & $\begin{array}{l}\text { BUD/FOR } \\
400 / 12 \mu \mathrm{g} \\
(N=899)\end{array}$ \\
\hline \multirow[t]{2}{*}{ Mean age, years $(\mathrm{SD})$} & $n=203$ & $n=203$ & $n=911$ & $n=899$ \\
\hline & $62.7(8.12)$ & $62.3(9.44)$ & $64.2(8.56)$ & $63.7(8.71)$ \\
\hline \multirow[t]{2}{*}{ Female, $n(\%)$} & $n=203$ & $n=203$ & $n=911$ & $n=899$ \\
\hline & $42(21)$ & $47(23)$ & $233(26)$ & $236(26)$ \\
\hline \multirow[t]{2}{*}{ Mean BMI, $\mathrm{kg} / \mathrm{m}^{2}(\mathrm{SD})$} & $n=203$ & $n=203$ & $n=908$ & $n=897$ \\
\hline & $26.91(4.83)$ & $26.74(4.50)$ & $26.86(5.18)$ & $26.98(5.10)$ \\
\hline GOLD grade, $n(\%)$ & $n=202$ & $n=203$ & $n=908$ & $n=897$ \\
\hline 1 & 0 & 0 & 0 & $1(<1)$ \\
\hline 2 & $74(37)$ & $75(37)$ & $298(33)$ & $291(32)$ \\
\hline $3 / 4$ & $128(63)$ & $128(63)$ & $610(67)$ & $605(68)$ \\
\hline $\begin{array}{l}\text { COPD exacerbation in } \\
\text { previous } 12 \text { months, } \\
n(\%)\end{array}$ & $n=203$ & $n=203$ & $n=911$ & $n=899$ \\
\hline$<2$ moderate, no severe & $68(33)$ & $71(35)$ & $418(46)$ & $421(47)$ \\
\hline $\begin{array}{l}\geq 2 \text { moderate or } \geq 1 \\
\text { severe }\end{array}$ & $135(67)$ & $132(65)$ & $493(54)$ & $478(53)$ \\
\hline \multirow{2}{*}{$\begin{array}{l}\text { Mean pre-bronchodilator } \\
\mathrm{FEV}_{1}[\mathrm{~mL}](\mathrm{SD})\end{array}$} & $n=202$ & $n=203$ & $n=909$ & $n=899$ \\
\hline & $1364(457.5)$ & $1351(522.6)$ & $1260(455.4)$ & $1240(462.8)$ \\
\hline \multirow{2}{*}{$\begin{array}{l}\text { Mean pre-bronchodilator } \\
\text { FEV }_{1} \text { predicted [\%] (SD) }\end{array}$} & $n=202$ & $n=203$ & $n=909$ & $n=899$ \\
\hline & $43.7(12.66)$ & $43.7(14.98)$ & $42.5(13.01)$ & $41.8(13.48)$ \\
\hline \multirow{2}{*}{$\begin{array}{l}\text { Mean pre-bronchodilator } \\
\text { FVC }[\mathrm{mL}](\mathrm{SD})\end{array}$} & $n=202$ & $n=203$ & $n=909$ & $n=899$ \\
\hline & $2989(764.7)$ & 3008 (908.5) & $2851(788.7)$ & $2858(828.6)$ \\
\hline \multirow[t]{2}{*}{ Mean reversibility [\%] (SD) } & $n=202$ & $n=203$ & $n=907$ & $n=897$ \\
\hline & $8.52(12.04)$ & $7.37(11.04)$ & $8.17(11.13)$ & $9.20(11.97)$ \\
\hline
\end{tabular}

$B M I$ body mass index, $B U D$ budesonide, $C O P D$ chronic obstructive pulmonary disease, $F E V_{1}$ forced expiratory volume in $1 \mathrm{~s}, F F$ fluticasone furoate, $F O R$ formoterol, $F V C$ forced vital capacity, GOLD Global Initiative for Chronic Obstructive Lung Disease, ITT intent-to-treat, $S D$ standard deviation, $U M E C$ umeclidinium, $V I$ vilanterol

\section{Efficacy}

Onset of Bronchodilation on Day 1

The proportion of patients achieving an increase of $\geq 100 \mathrm{~mL}$ over baseline in $\mathrm{FEV}_{1}$ at any time point during the first $6 \mathrm{~h}$ post dose on day 1 was greater with FF/UMEC/VI (90\%) than with BUD/FOR (76\%). The odds of attaining versus not attaining this increase was statistically significant in favor of FF/UMEC/VI versus 
BUD/FOR [odds ratio 2.79; 95\% confidence interval (CI) 1.56-4.98; $p<0.001$ ]. In total, 104 $(51 \%)$ and 81 (40\%) patients in the FF/UMEC/VI and BUD/FOR arms, respectively, achieved a $\geq 100 \mathrm{~mL}$ increase over baseline in $\mathrm{FEV}_{1}$ by 15 min post dose. A further 33 (16\%), 25 (12\%), $13(6 \%)$, and $6(3 \%)$ patients receiving FF/UMEC/VI and 27 (13\%), 17 (8\%), 21 (10\%), and $6(3 \%)$ patients receiving BUD/FOR achieved this increase at $30 \mathrm{~min}, 1,3$, and $6 \mathrm{~h}$ post dose. The median time to onset of bronchodilation $\left(\mathrm{FEV}_{1}\right.$ change from baseline $\geq 100 \mathrm{~mL}$ ) during $0-6 \mathrm{~h}$ on day 1 was $30 \mathrm{~min}$ with FF/UMEC/VI and 39 min with BUD/FOR (Fig. 1).

\section{Mean Change from Baseline in Serial FEV} On day 1 , the difference in least square (LS) mean change from baseline in $\mathrm{FEV}_{1}$ between FF/UMEC/VI and BUD/FOR (range 15-130 mL) was statistically significant $(p<0.05)$ at all time points, except 15, $30 \mathrm{~min}$, and $15 \mathrm{~h}$ (Fig. 2a). At week 24 , the LS mean increases from baseline ranged from 160 to $339 \mathrm{~mL}$ with FF/UMEC/VI, and -32 to $140 \mathrm{~mL}$ with BUD/FOR; the difference between FF/UMEC/VI and BUD/FOR (range 156-231 mL) was statistically significant $(p<0.001)$ at every time point (Fig. 2b). Furthermore, between-group differences at week 24 favoring $\mathrm{FF} / \mathrm{UMEC} / \mathrm{VI}$ were greater than those observed on day 1 . LS mean changes from baseline in $\mathrm{FEV}_{1}$ with $\mathrm{FF} / \mathrm{UMEC} / \mathrm{VI}$ and BUD/FOR over time showed that the benefit with FF/UMEC/VI increased from day 1 to week 24 , while over the same period the benefit with BUD/FOR declined (Fig. 2).

\section{Mean Change from Baseline in Serial FEV by Disease Severity at Screening}

In the subgroup of patients with $\mathrm{FEV}_{1}<50 \%$ predicted and no moderate or severe exacerbation in the prior year, the LS mean change from baseline ranged from 92 to $210 \mathrm{~mL}$ on day 1 and 86 to $222 \mathrm{~mL}$ at week 24 with FF/UMEC/VI, and - 27 to $162 \mathrm{~mL}$ on day 1 and -81 to $95 \mathrm{~mL}$ at week 24 with BUD/FOR. On day 1, the difference between FF/UMEC/VI and BUD/FOR (range -42 to $179 \mathrm{~mL}$ ) was statistically significant at $6,12,21$, and $23 \mathrm{~h}$ (Fig. 3a). At week 24, the difference between FF/UMEC/VI and BUD/FOR (range 94-196 mL) was statistically significant at every time point except $30 \mathrm{~min}$ (Fig. 4a).

In the subgroup of patients with $\mathrm{FEV}_{1}<50 \%$ predicted and $\geq 1$ moderate or severe exacerbation in the prior year, the LS mean change from baseline ranged from 71 to $182 \mathrm{~mL}$ on day 1 and 171 to $319 \mathrm{~mL}$ at week 24 with

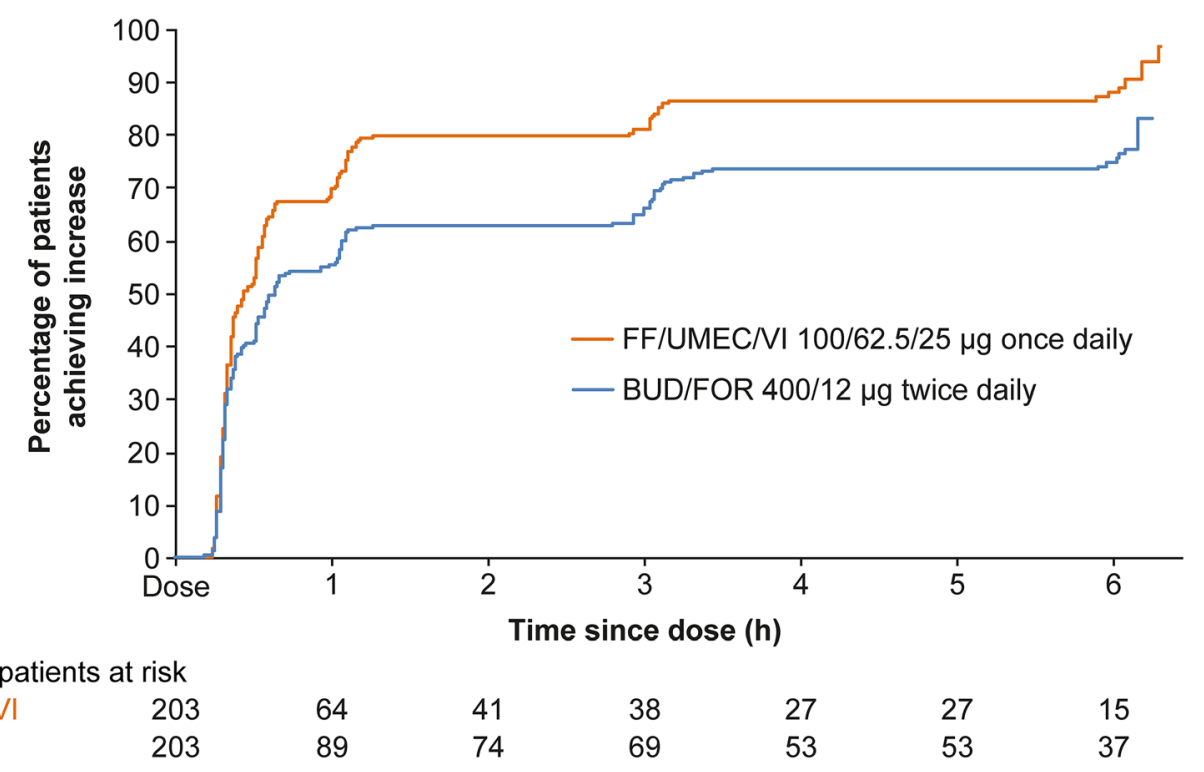

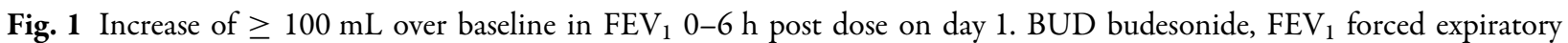
volume in $1 \mathrm{~s}$, FF fluticasone furoate, FOR formoterol, UMEC umeclidinium, VI vilanterol 
a Day 1
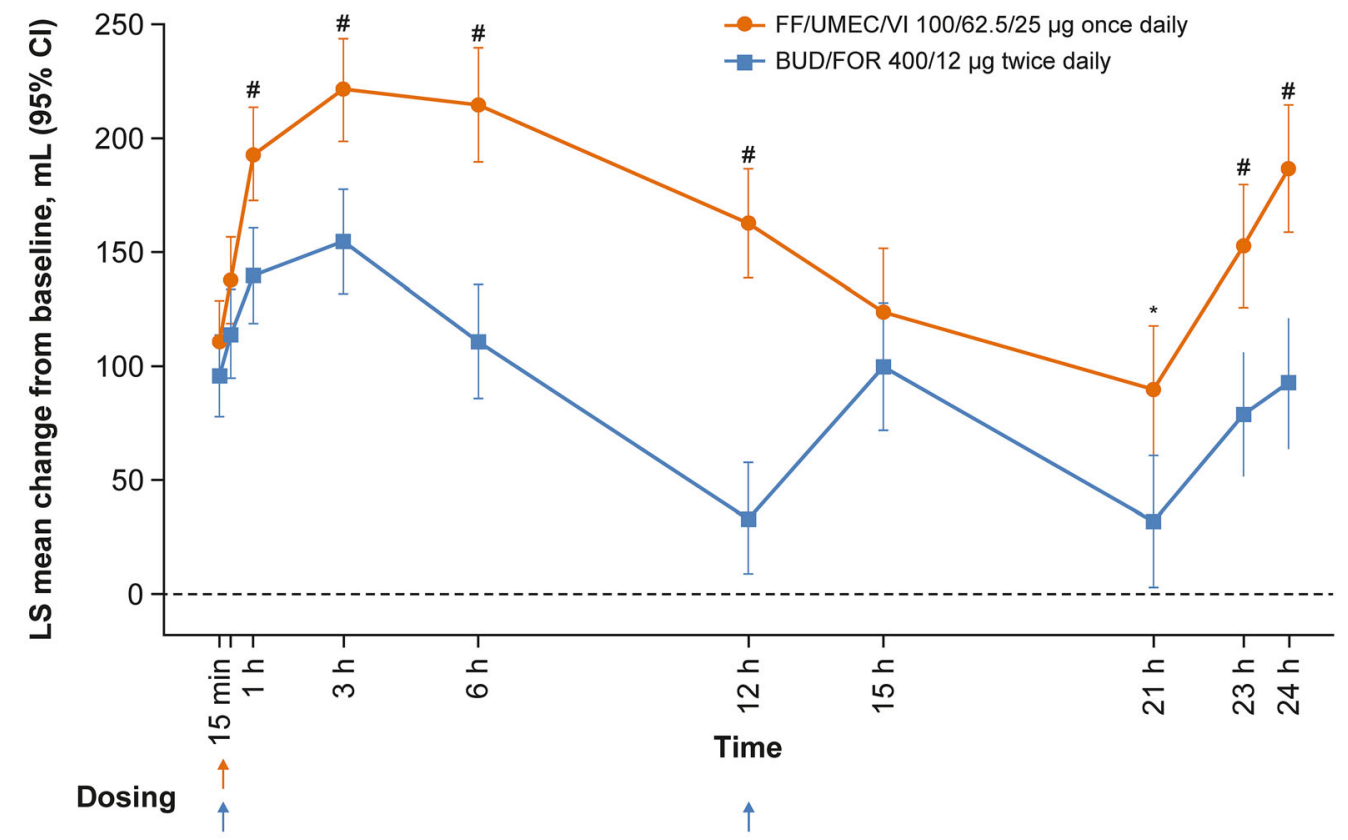

\section{b Week 24}

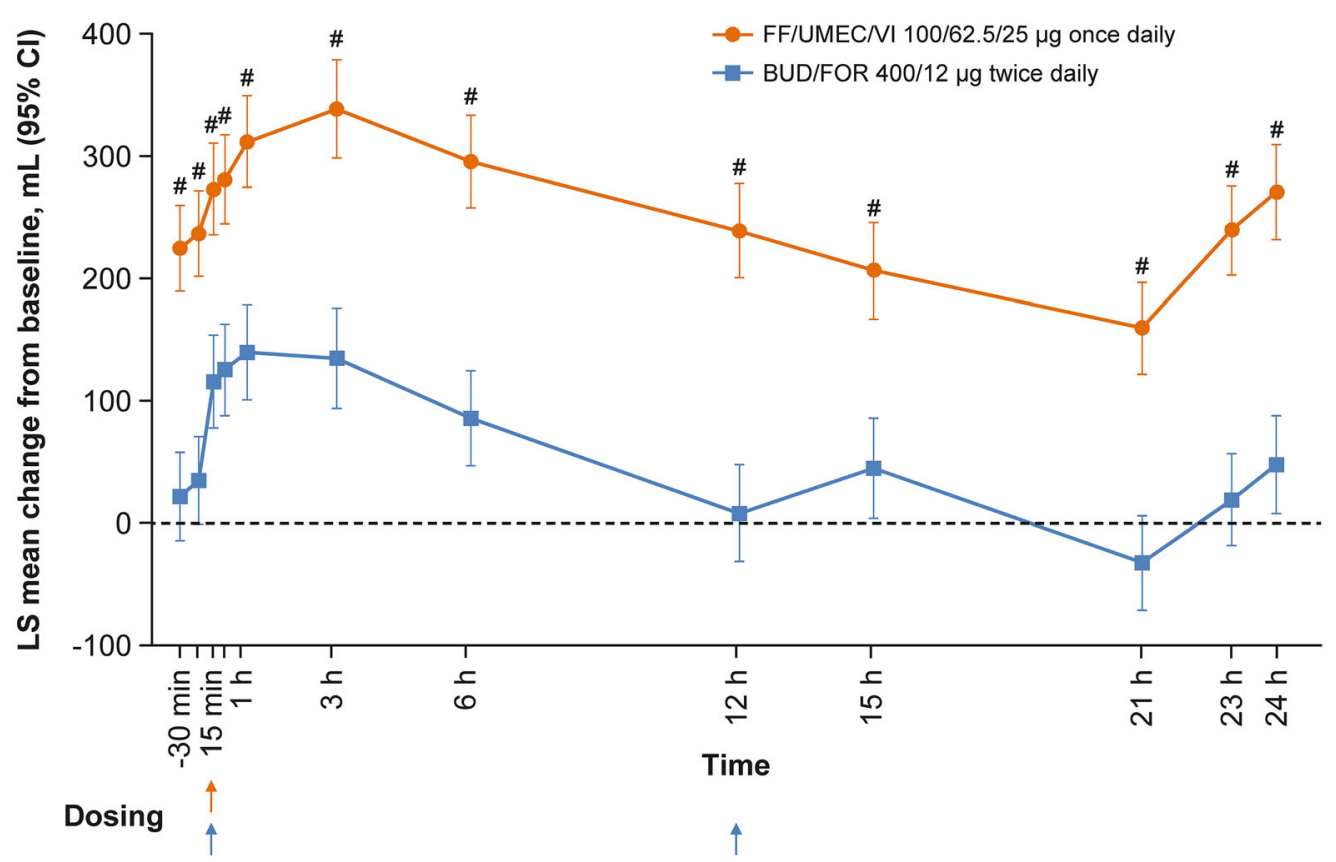

Fig. 2 LS mean change from baseline in $\mathrm{FEV}_{1}$ over $24 \mathrm{~h}$ on day 1 (a) and at week $24(\mathbf{b})$. First doses of FF/UMEC/VI and BUD/FOR given at $0 \mathrm{~h}$; second dose of BUD/FOR given approx. $12 \mathrm{~h}$ later. ${ }^{*} p<0.05$ and ${ }^{\#} p<0.001$ for comparison with BUD/FOR. BUD budesonide, CI confidence interval, $\mathrm{FEV}_{1}$ forced expiratory volume in $1 \mathrm{~s}$,
FF fluticasone furoate, FOR formoterol, LS least squares, UMEC umeclidinium, VI vilanterol. Figure reproduced with permission from the authors (David A. Lipson, et al. Am J Respir Crit Care Med. 2017;195:A3605) 
FF/UMEC/VI, and 13 to $145 \mathrm{~mL}$ on day 1 and 11 to $154 \mathrm{~mL}$ at week 24 with BUD/FOR. On day 1 , the difference between FF/UMEC/VI and BUD/FOR (range 11-100 mL) was statistically significant at 1, 6, 12, 21, 23, and $24 \mathrm{~h}$ (Fig. 3b). At week 24, the difference between FF/UMEC/VI and BUD/FOR (range 115-206 mL) was statistically significant at every time point (Fig. 4b).

In the subgroup of patients with $\mathrm{FEV}_{1} \geq 50 \%$ and $<80 \%$ predicted and $\geq 2$ moderate or $\geq 1$ severe exacerbations in the prior year, the LS mean change from baseline ranged from 116 to $285 \mathrm{~mL}$ on day 1 and 195 to $427 \mathrm{~mL}$ at week 24 with FF/UMEC/VI, and 47 to $178 \mathrm{~mL}$ on day 1 and -59 to $155 \mathrm{~mL}$ at week 24 with BUD/FOR. On day 1 , the difference between FF/UMEC/VI and BUD/FOR (range 7-144 mL) was statistically significant at 1, 3, 6, 12, and $24 \mathrm{~h}$ (Fig. 3c). At week 24, the difference between FF/UMEC/VI and BUD/FOR (range 212-293 mL) was statistically significant at every time point (Fig. 4c).

\section{Weighted Mean FEV}

FF/UMEC/VI demonstrated statistically significant improvements over BUD/FOR in weighted mean $\mathrm{FEV}_{1}$ at all assessed post-dose intervals $(0-6,0-12,12-24$, and $0-24 \mathrm{~h})$ on both day 1 and at week 24 (Table 2). Between-group differences on weighted mean $\mathrm{FEV}_{1}$ were more marked at week 24 (range $196-210 \mathrm{~mL}$; all $p<0.001$ ) than on day 1 (range $56-93 \mathrm{~mL}$; all $p \leq 0.002$; Table 2).

\section{Change from Baseline to Peak FEV}

The change from baseline to peak $\mathrm{FEV}_{1}$ post dose was greater with FF/UMEC/VI than with BUD/FOR on day 1 (280 vs $218 \mathrm{~mL}$ ) and at week 24 (389 vs $211 \mathrm{~mL}$ ), and the difference between treatments was statistically significant at both time points [day 1: $62 \mathrm{~mL}(95 \%$ CI 30-93); week 24: $178 \mathrm{~mL}$ (95\% CI 123-233); both $p<0.001$ ] (Table 3). At week 24, changes with FF/UMEC/VI were larger than on day 1 (389 vs $280 \mathrm{~mL}$ ) while the changes seen with BUD/FOR were similar to day 1 (211 vs $218 \mathrm{~mL}$ ).

\section{Mean Change from Baseline in Serial FVC}

On day 1, larger mean increases from baseline in FVC were seen with FF/UMEC/VI (range
130-338 mL) compared with BUD/FOR (range - 4 to $195 \mathrm{~mL}$ ); between-group differences were statistically significant at every time point, except $15 \mathrm{~min}$ and $15 \mathrm{~h}$ (range 30-208 mL; Fig. 5a).

At week 24, a pattern of response in FVC was observed similar to that on day 1 , and the differences between treatments were more marked. Treatment with FF/UMEC/VI produced larger mean increases from baseline in FVC (range 136-374 mL) compared with BUD/FOR (range - 133 to $137 \mathrm{~mL}$ ) and the differences between FF/UMEC/VI and BUD/FOR (range 139-309 mL) were statistically significant at every time point $(p \leq 0.002$; Fig. 5b).

\section{Safety}

Safety results in the ITT population have been presented previously [5]. Briefly, the incidence of adverse events and incidence of serious adverse events were similar between treatment arms. The incidence of adverse events of special interest was also similar across treatment arms, including pneumonia, which was seen in $2.2 \%$ and $0.8 \%$ of patients who received FF/UMEC/VI and BUD/FOR at week 24 , respectively. In the 52-week extension population, the incidence of pneumonia was $1.9 \%$ with $\mathrm{FF} / \mathrm{UMEC} / \mathrm{VI}$ and $1.8 \%$ with BUD/FOR [5].

\section{DISCUSSION}

The FULFIL trial demonstrated statistically significant and clinically meaningful improvements in lung function, quality of life, and reduction of exacerbations with FF/UMEC/VI versus BUD/FOR in symptomatic patients with COPD at risk of exacerbations [5]. The present prespecified analysis of 24-h serial spirometry demonstrates the sustained effect of once-daily FF/UMEC/VI versus twice-daily BUD/FOR, with statistically significantly greater improvements in lung function over the 24-h dosing period. $\mathrm{FF} / \mathrm{UMEC} / \mathrm{VI}$ was associated with significantly greater improvements in lung function at all time points by week 24 compared with twicedaily BUD/FOR, even though patients received a second dose of BUD/FOR during the 24-h 
a $\mathrm{FEV}_{1}<50 \%$ predicted and no moderate or severe exacerbation in prior year

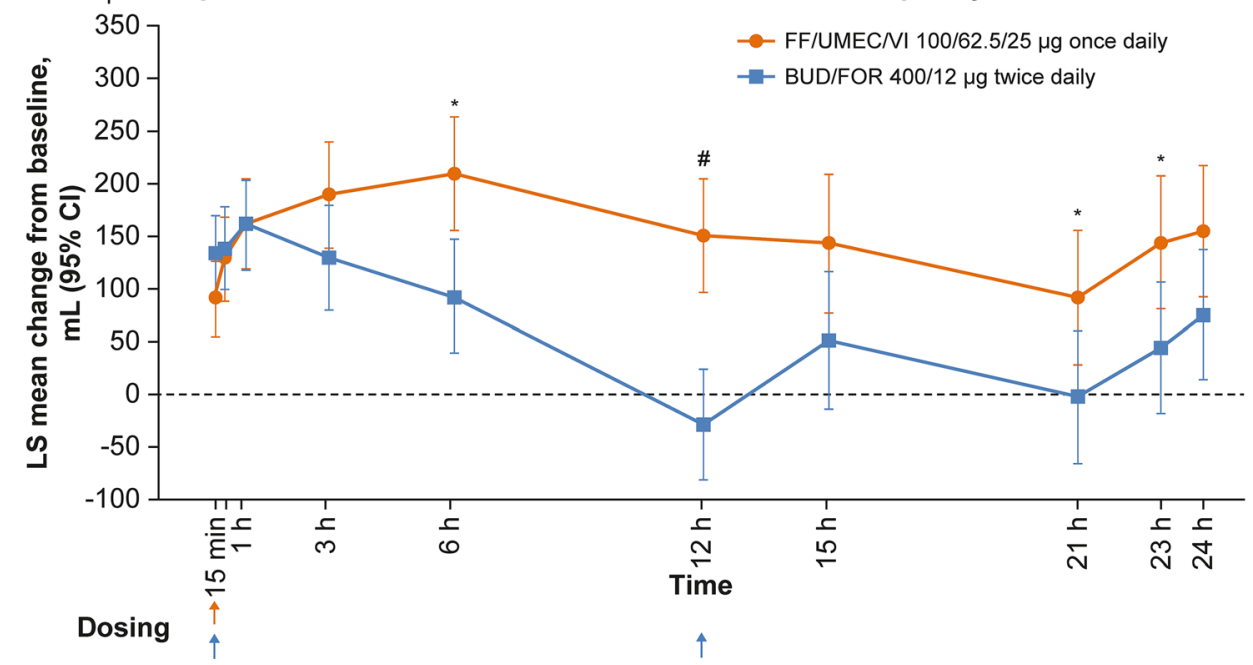

b FEV $1<50 \%$ predicted and $\geq 1$ moderate or severe exacerbation in prior year

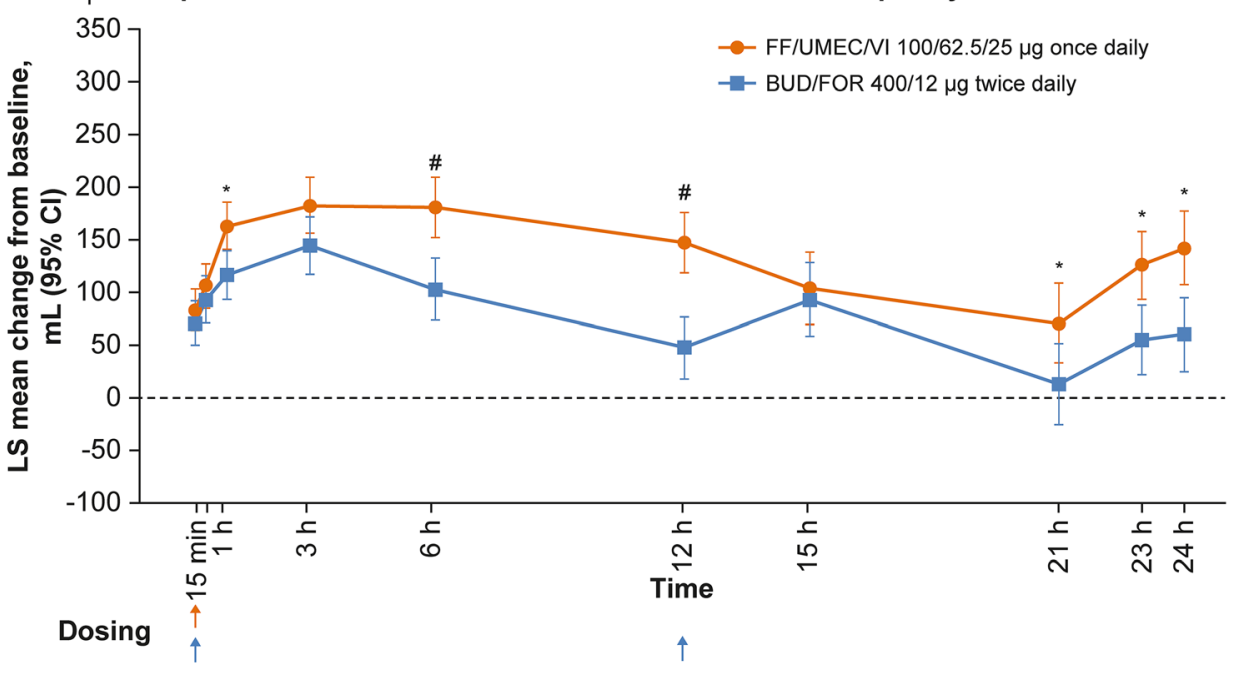

C FEV $_{1} \geq 50 \%$ and $<80 \%$ predicted and $\geq 2$ moderate or $\geq 1$ severe exacerbations in prior year

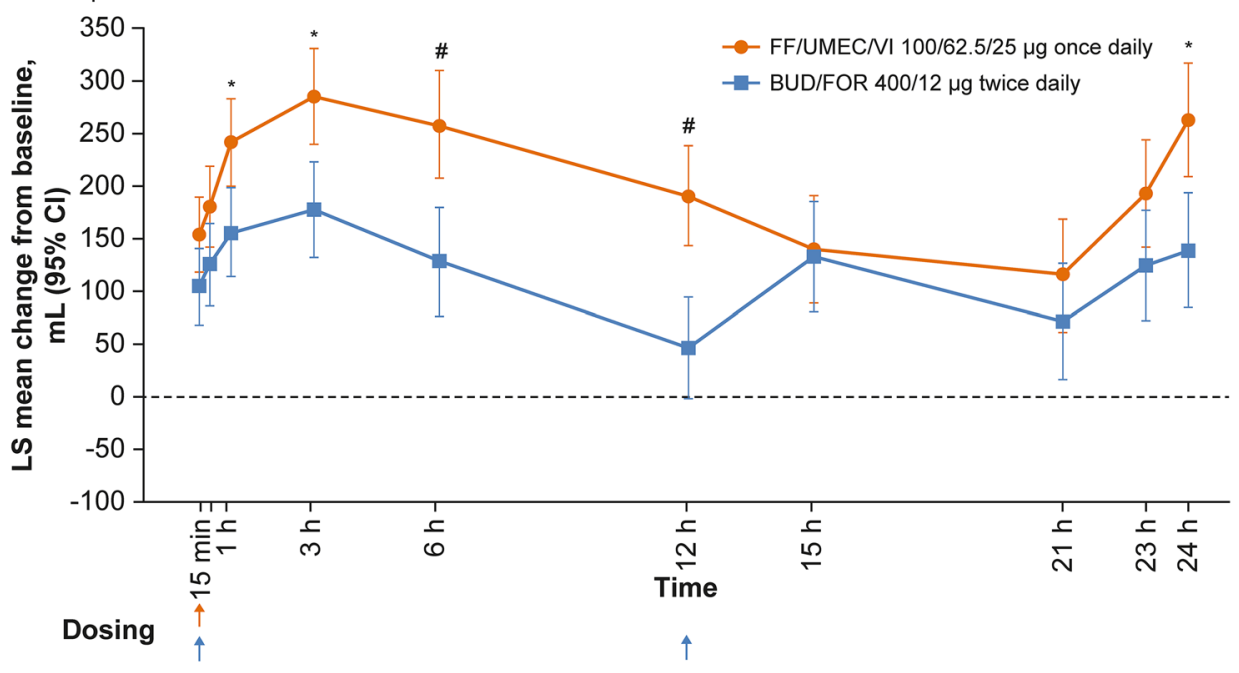


4Fig. 3 LS mean change from baseline in $\mathrm{FEV}_{1}$ over $24 \mathrm{~h}$ on day 1 by disease severity at screening. First doses of $\mathrm{FF} / \mathrm{UMEC} / \mathrm{VI}$ and BUD/FOR given at $0 \mathrm{~h}$; second dose of $\mathrm{BUD} / \mathrm{FOR}$ given approx. $12 \mathrm{~h}$ later. ${ }^{*} p<0.05$ and ${ }^{\#} p<0.001$ for comparison with BUD/FOR. BUD budesonide, $\mathrm{CI}$ confidence interval, $\mathrm{FEV}_{1}$ forced expiratory volume in $1 \mathrm{~s}$, FF fluticasone furoate, FOR formoterol, LS least squares, UMEC umeclidinium, VI vilanterol

spirometry assessment. This provides further evidence for the lung function benefits of oncedaily $\mathrm{FF} / \mathrm{UMEC} / \mathrm{VI}$ triple therapy in patients with COPD. These greater lung function benefits with FF/UMEC/VI are in line with the primary findings of the FULFIL trial [5], which demonstrated significant between-group differences in mean change from baseline in trough $\mathrm{FEV}_{1}$ at week 24. Furthermore, the results illustrate the benefit of adding a second bronchodilator (UMEC) for improving airflow in this patient population.

FF/UMEC/VI was associated with clinically meaningful and significant improvements in $\mathrm{FEV}_{1}$ over twice-daily BUD/FOR at all time points, including at $15 \mathrm{~h}$, which would occur shortly after the administration of the second dose of BUD/FOR. Indeed, the serial $\mathrm{FEV}_{1}$ profiles over $24 \mathrm{~h}$ suggest that there is a loss of treatment effect with twice-daily BUD/FOR after $12 \mathrm{~h}$, as shown by a substantial decline in $\mathrm{FEV}_{1}$, and that the second dose of BUD/FOR may only be recovering patients to their baseline level. Further evidence for the sustained effect of once-daily FF/UMEC/VI therapy is provided by the clinically meaningful treatment differences in weighted mean $\mathrm{FEV}_{1}$ seen during each time period. Taken together, results from this prespecified analysis suggest that once-daily $\mathrm{FF} /$ UMEC/VI therapy decreases the variability of the treatment effect and prevents lung function decline that may be associated with twice-daily therapies $[9,10]$.

These results are also in line with data reported in a post hoc analysis from four pooled trials, which demonstrated greater 24-h efficacy with triple therapy compared with ICS/LABA therapy in symptomatic patients with COPD at risk of exacerbations [6]. Furthermore, two recent replicate phase IV 12-week, randomized trials have investigated once-daily singleinhaler triple therapy with FF/UMEC/VI compared with twice-daily BUD/FOR plus oncedaily tiotropium therapy, with FF/UMEC/VI demonstrating a significantly greater improvement in $\mathrm{FEV}_{1}$ at $12 \mathrm{~h}$ (prior to the second dose of BUD/FOR) and between 21 and $24 \mathrm{~h}$, in symptomatic patients with COPD [11].

It is also important to note that there was an increased treatment benefit at each time point by week 24 compared with day 1 with FF/UMEC/VI while a decreased treatment benefit was seen for twice-daily BUD/FOR. Treatment differences in mean change from baseline in peak $\mathrm{FEV}_{1}$ and weighted mean $\mathrm{FEV}_{1}$ over the 24-h time period also increased between day 1 and week 24 . These data suggest that triple therapy with FF/UMEC/VI may provide more sustained long-term lung function benefits compared with dual therapy with twice-daily BUD/FOR in symptomatic patients with COPD at risk of exacerbations. At week 24, the significant between-group difference in $\mathrm{FEV}_{1} 30 \mathrm{~min}$ before administration of the morning dose demonstrates that at true trough levels, significant improvements in airflow are seen in patients receiving once-daily $\mathrm{FF} / \mathrm{UMEC} / \mathrm{VI}$ versus twice-daily BUD/FOR.

At the 21-h time point, the LS mean change from baseline in $\mathrm{FEV}_{1}$ for the BUD/FOR arm was below zero, that is, representing an overall worsening in $\mathrm{FEV}_{1}$ versus baseline. Although the exact reason for this $\mathrm{FEV}_{1}$ drop is unclear, it is known that patients experience daily physiological diurnal fluctuations in pulmonary function, with the lowest $\mathrm{FEV}_{1}$ measurements after $20 \mathrm{~h}$ before increasing again over the next $4 \mathrm{~h}$ [12], which is similar to the 24 -h profiles seen in this study. On day 1 , significantly greater improvements in serial $\mathrm{FEV}_{1}$ measurements with FF/UMEC/VI compared with twicedaily BUD/FOR were also seen at nearly all time points, suggesting that $\mathrm{FF} / \mathrm{UMEC} / \mathrm{VI}$ provides not only a greater treatment benefit but also a more rapid onset of action than twice-daily BUD/FOR. This is further supported by the greater proportion of patients achieving a clinically meaningful increase of $\geq 100 \mathrm{~mL}$ in $\mathrm{FEV}_{1}$ during the first $6 \mathrm{~h}$ after administration of FF/UMEC/VI on day 1 compared with twice- 
a $\mathrm{FEV}_{1}<50 \%$ predicted and no moderate or severe exacerbation in prior year

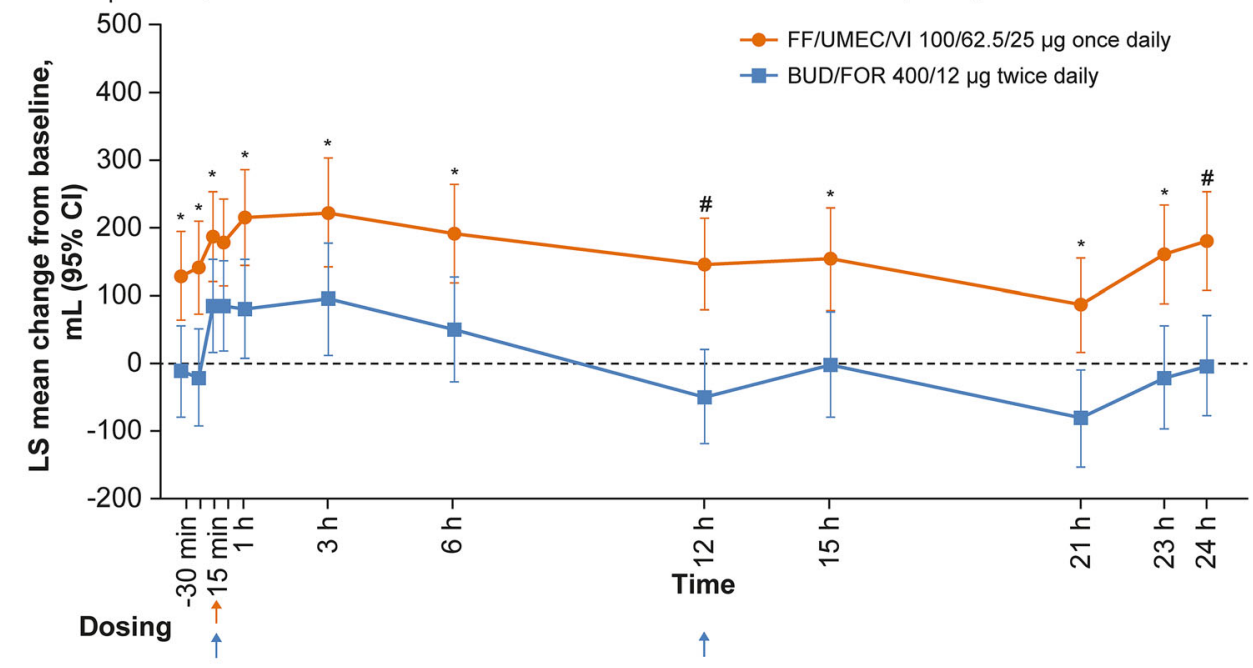

b $\mathrm{FEV}_{1}<50 \%$ predicted and $\geq 1$ moderate or severe exacerbation in prior year

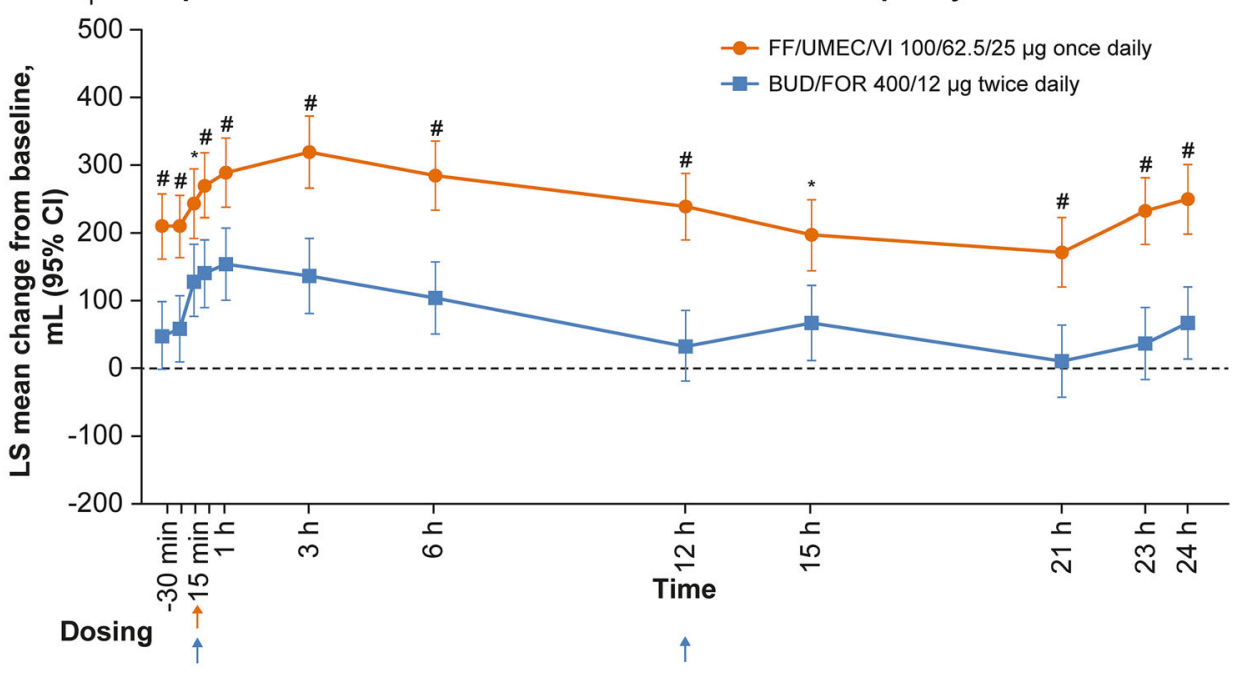

C $\mathrm{FEV}_{1} \geq 50 \%$ and $<80 \%$ predicted and $\geq 2$ moderate or $\geq 1$ severe exacerbations in prior year

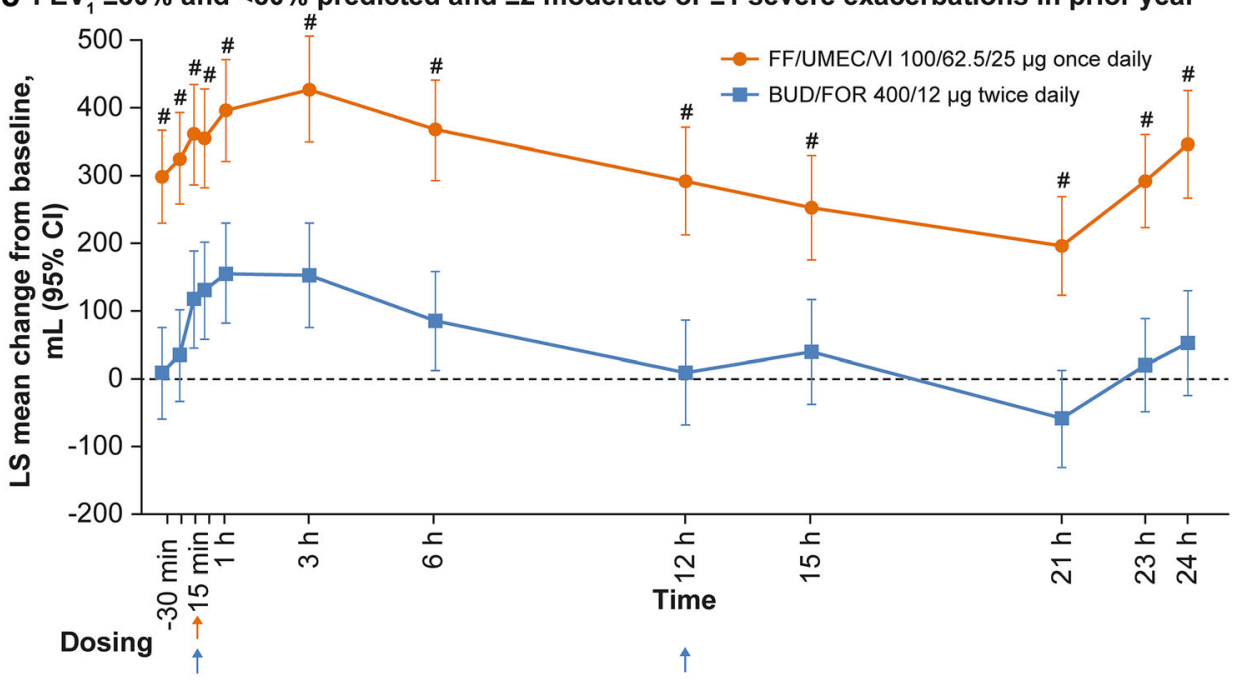


4Fig. 4 LS mean change from baseline in $\mathrm{FEV}_{1}$ over $24 \mathrm{~h}$ at week 24 by disease severity at screening. First doses of $\mathrm{FF} / \mathrm{UMEC} / \mathrm{VI}$ and $\mathrm{BUD} / \mathrm{FOR}$ given at $0 \mathrm{~h}$; second dose of $\mathrm{BUD} / \mathrm{FOR}$ given approx. $12 \mathrm{~h}$ later. ${ }^{*} p<0.05$ and ${ }^{\#} p<0.001$ for comparison with BUD/FOR. BUD budesonide, $\mathrm{CI}$ confidence interval, $\mathrm{FEV}_{1}$ forced expiratory volume in $1 \mathrm{~s}$, FF fluticasone furoate, FOR formoterol, LS least squares, UMEC umeclidinium, VI vilanterol

daily BUD/FOR (90\% vs 76\%) and the shorter median time to achieve this increase (30 vs $39 \mathrm{~min})$. The rapid onset of a medication has been suggested as a potential encouragement for patients adhering to their treatment $[13,14]$, while a longer duration of action may provide greater tolerance for patients not adhering to their treatment schedule [14]. As adherence is not only related to the dosage of medication but also the timing of the administration [15], simplifying treatment regimens from a twicedaily to once-daily regimen may improve adherence and potentially clinical outcomes [16-18]. However, it should be noted that the FULFIL study, with its double-dummy administration, was not designed to assess the effect of once-daily or twice-daily therapy on adherence.

The analysis of serial $\mathrm{FEV}_{1}$ by disease severity at screening demonstrates a lung function benefit for once-daily FF/UMEC/VI compared with twice-daily BUD/FOR in patients with varying degrees of COPD severity, specifically

Table 2 Treatment differences in weighted mean $\mathrm{FEV}_{1}$ over the 24-h time period on day 1 and at week 24

\begin{tabular}{|c|c|c|c|c|}
\hline \multirow[t]{2}{*}{ Weighted mean FEV 1} & \multicolumn{4}{|c|}{ FF/UMEC/VI vs BUD/FOR at post-dose time points } \\
\hline & $0-6 h$ & 0-12 h & $0-24 \mathrm{~h}$ & $12-24 \mathrm{~h}$ \\
\hline Day $1(\mathrm{~mL})(95 \% \mathrm{CI})$, & $67(39-95)$ & $93(64-122)$ & $75(45-105)$ & $56(21-91)$ \\
\hline$p$ value & $<0.001$ & $<0.001$ & $<0.001$ & 0.002 \\
\hline Week 24 (mL) (95\% CI), & $196(142-250)$ & $210(157-262)$ & $205(154-256)$ & $199(147-251)$ \\
\hline$p$ value & $<0.001$ & $<0.001$ & $<0.001$ & $<0.001$ \\
\hline
\end{tabular}

BUD budesonide, $C I$ confidence interval, $F E V_{1}$ forced expiratory volume in $1 \mathrm{~s}, F F$ fluticasone furoate, FOR formoterol, $U M E C$ umeclidinium, $V I$ vilanterol

Table 3 Peak $\mathrm{FEV}_{1}$ on day 1 and at week 24

\begin{tabular}{|c|c|c|}
\hline Peak FEV $_{1}(\mathrm{~mL})$ & $\begin{array}{l}\text { FF/UMEC/VI } 100 / 62.5 / 25 \mu \mathrm{g} \\
(N=203)\end{array}$ & $\begin{array}{l}\text { BUD/FOR } 400 / 12 \mu \mathrm{g} \\
(N=203)\end{array}$ \\
\hline \multicolumn{3}{|l|}{ Day 1} \\
\hline LS mean change $(95 \% \mathrm{CI})$ & $280(258-301)$ & $218(196-240)$ \\
\hline $\begin{array}{l}\text { FF/UMEC/VI vs BUD/FOR difference ( } 95 \% \\
\mathrm{CI}), p \text { value }\end{array}$ & $62(30-93),<0.001$ & \\
\hline \multicolumn{3}{|l|}{ Week 24} \\
\hline LS mean change $(95 \% \mathrm{CI})$ & $389(350-427)$ & $211(172-250)$ \\
\hline $\begin{array}{l}\text { FF/UMEC/VI vs BUD/FOR difference ( } 95 \% \\
\mathrm{CI}), p \text { value }\end{array}$ & $178(123-233),<0.001$ & \\
\hline
\end{tabular}

BUD budesonide, $C I$ confidence interval, $F E V_{1}$ forced expiratory volume in $1 \mathrm{~s}, F F$ fluticasone furoate, $F O R$ formoterol, $L S$ least squares, $U M E C$ umeclidinium, $V I$ vilanterol 
a Day 1
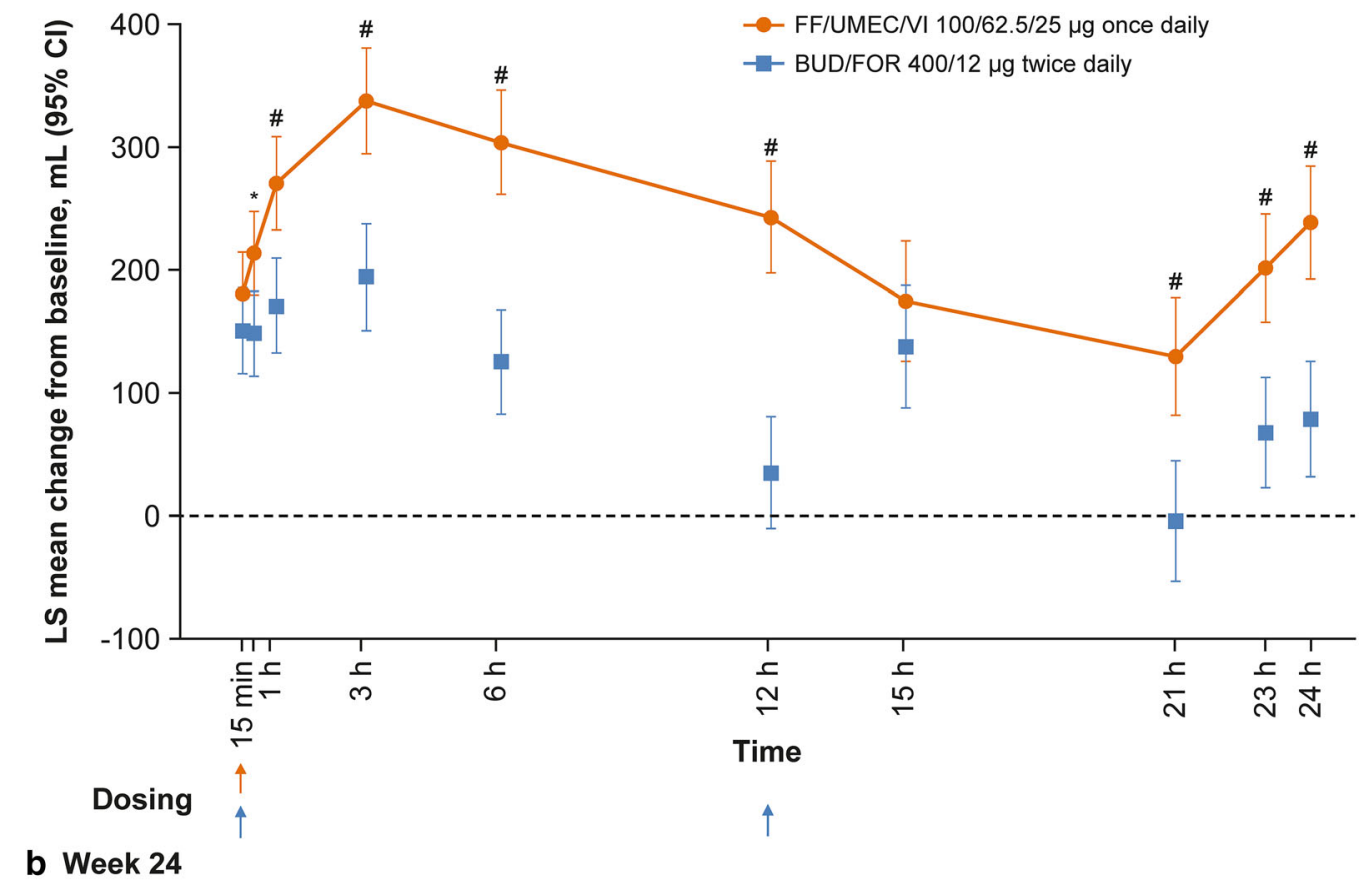

b Week 24

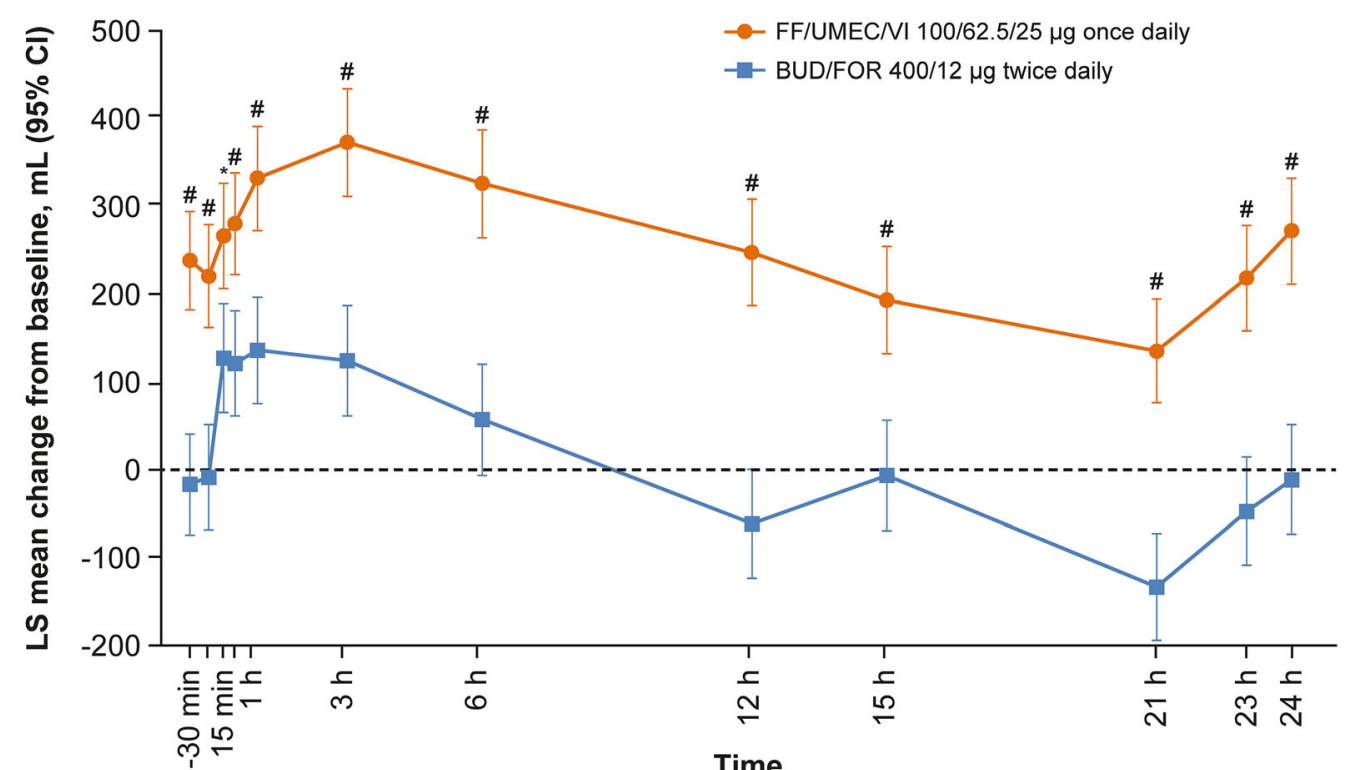

\section{Dosing}

Fig. 5 LS mean change from baseline in FVC over $24 \mathrm{~h}$ on day 1 (a) and at week 24 (b). First doses of $\mathrm{FF} / \mathrm{UMEC} / \mathrm{VI}$ and BUD/FOR given at $0 \mathrm{~h}$; second dose of $\mathrm{BUD} / \mathrm{FOR}$ given approx. $12 \mathrm{~h}$ later. ${ }^{*} p<0.05$ and

patients with severe or very severe airflow limitation and no history of exacerbation in the prior year, those with severe or very severe
Time

\section{$\uparrow$}

${ }^{\#} p \leq 0.001$ for comparison with BUD/FOR. BUD budesonide, CI confidence interval, FVC forced vital capacity, FF fluticasone furoate, FOR formoterol, LS least squares, UMEC umeclidinium, VI vilanterol

airflow limitation and a history of exacerbation in the prior year, and those with moderate airflow limitation and a history of frequent or 
hospitalized exacerbations in the prior year. Consistent with results in the overall serial spirometry subgroup, the lung function benefits of FF/UMEC/VI versus BUD/FOR started from day 1 and were sustained through to week 24 , with between-treatment differences becoming greater over time. Perhaps unsurprisingly, greater improvements in lung function were seen in patients with moderate airflow limitation, who had a history of frequent or severe exacerbations. Importantly, the week 24 data show that even at trough $(30 \mathrm{~min}$ before dosing), FF/UMEC/VI provided clinically relevant differences in $\mathrm{FEV}_{1}$ compared with $\mathrm{BUD} / \mathrm{FOR}$, demonstrating the benefit of single-inhaler FF/UMEC/VI triple therapy over the entire 24-h dosing interval across a range of disease severities.

Effects on FVC were consistent and supportive of the $\mathrm{FEV}_{1}$ findings, with a significantly increased treatment benefit for FF/UMEC/VI, but a decreased treatment benefit for twice-daily BUD/FOR, noted at each time point by week 24 versus day 1 . These data point to improvements in airflow obstruction and suggest a decrease in air trapping with once-daily FF/UMEC/VI over twice-daily BUD/FOR in symptomatic patients with COPD at risk of exacerbations.

Safety outcomes from the overall FULFIL ITT population demonstrated that there were no clinically relevant safety differences between the two treatment arms. The safety profile of FF/UMEC/VI was consistent with the known profiles of the individual molecules [5].

This subanalysis of the FULFIL study is one of the first to report 24-h serial $\mathrm{FEV}_{1}$ measurements for triple versus dual therapies in a well-characterized population from a large, global clinical trial of symptomatic patients with COPD at risk of exacerbations. A strength of 24-h spirometry measurement is that it allows the characterization of lung function improvements over the entire dosing period of a therapy and allows for the observation of diurnal variation in lung function. This provides more detailed insights into the time of response onset and the length of the treatment response, compared with weighted mean or trough $\mathrm{FEV}_{1}$ measurements. Owing to the inclusive study design, FULFIL enabled the inclusion of a broad patient population.
Furthermore, FULFIL was also designed to closely resemble standard care, with patients continuing their prestudy therapies up to randomization, in order to mimic clinical switching scenarios and improve the generalizability of the study results [5]. Nonetheless, there are some limitations to note. These include the potential for patient selection bias as serial 24-h spirometry assessments were undertaken in consenting patients from selected centers only. Indeed, mean increases from baseline in trough $\mathrm{FEV}_{1}$ at week 24 were higher in the subgroup of patients included in this prespecified analysis $(225 \mathrm{~mL}$ with FF/UMEC/VI vs $22 \mathrm{~mL}$ with BUD/FOR at trough, $30 \mathrm{~min}$ before the next scheduled dose) than in the overall FULFIL population $(142 \mathrm{~mL}$ with FF/UMEC/VI vs $-29 \mathrm{~mL}$ with BUD/FOR). This could be attributed to the higher baseline pre-bronchodilator $\mathrm{FEV}_{1}$ values in the serial spirometry subgroup compared with the overall ITT population. However, as both treatment groups were impacted by this difference, it is unlikely to have affected between-treatment comparisons. Finally, the post hoc nature of the analysis of serial $\mathrm{FEV}_{1}$ by disease severity should also be considered when interpreting the results.

\section{CONCLUSION}

Treatment with once-daily FF/UMEC/VI provided statistically significant and clinically relevant improvements in lung function versus twice-daily BUD/FOR. These improvements were sustained throughout the 24-h dosing period, and were observed from the first day of treatment, increasing through to week 24 . Results were also consistent across a range of disease severities. Once-daily FF/UMEC/VI treatment exhibited a more rapid onset of action than twice-daily BUD/FOR, translating into significantly more patients achieving clinically relevant benefits in lung function within the first $6 \mathrm{~h}$ post administration with triple therapy versus dual therapy. These data further support the lung function benefits of once-daily FF/UMEC/VI single-inhaler triple therapy in symptomatic patients with COPD at risk of exacerbations. 


\section{ACKNOWLEDGEMENTS}

The authors would like to thank the participants of the FULFIL study.

Funding. This study was funded by GlaxoSmithKline (GSK; CTT116853; clinicaltrials.gov NCT02345161). The funders of the study had a role in the study design, data analysis, data interpretation and writing of the report. GlaxoSmithKline also funded the journal's Rapid Service and Open Access fees.

Editorial Support. Editorial support (in the form of writing assistance, assembling tables and figures, collating author comments, grammatical editing, and referencing) was provided by Philip Chapman at Fishawack Indicia Ltd, UK, and was funded by GSK.

Authorship. The authors meet criteria for authorship as recommended by the International Committee of Medical Journal Editors, take responsibility for the integrity of the work as a whole, contributed to the writing and reviewing of the manuscript, and have given final approval for the version to be published. All authors were involved in the acquisition and analysis/interpretation of data and take complete responsibility for the integrity of the data and accuracy of the data analysis.

Prior Presentation. Data from this manuscript were previously presented in part at the American Thoracic Society International Conference, Washington, DC, USA, May 19-24, 2017.

Disclosures. D.A. Lipson, R. Birk, N. Brealey, and C.-Q. Zhu are employees of GSK and hold stock options/shares in GSK. ELLIPTA is owned by or licensed to the GSK group of companies. Turbuhaler is a trademark of AstraZeneca UK Ltd.

Compliance with Ethics Guidelines. This study was conducted in accordance with the Declaration of Helsinki and Good Clinical Practice guidelines. Individual institutional review boards at each clinical site approved the protocol. Written consent was obtained from the subjects or their surrogates as required by the institutional review boards.

Data Availability. Anonymized individual participant data and study documents can be requested for further research from http://www. clinicalstudydatarequest.com.

Open Access. This article is licensed under a Creative Commons Attribution-NonCommercial 4.0 International License, which permits any non-commercial use, sharing, adaptation, distribution and reproduction in any medium or format, as long as you give appropriate credit to the original author(s) and the source, provide a link to the Creative Commons licence, and indicate if changes were made. The images or other third party material in this article are included in the article's Creative Commons licence, unless indicated otherwise in a credit line to the material. If material is not included in the article's Creative Commons licence and your intended use is not permitted by statutory regulation or exceeds the permitted use, you will need to obtain permission directly from the copyright holder. To view a copy of this licence, visit http:// creativecommons.org/licenses/by-nc/4.0/.

\section{REFERENCES}

1. Global Initiative for Chronic Obstructive Lung Disease. Global strategy for the diagnosis, management and prevention of chronic obstructive pulmonary disease (2020 report). 2020. http:// goldcopd.org/. Accessed Feb 2020.

2. Simeone JC, Luthra R, Kaila S, et al. Initiation of triple therapy maintenance treatment among patients with COPD in the US. Int J Chron Obstr Pulm Dis. 2017;12:73-83.

3. Wurst KE, Punekar YS, Shukla A. Treatment evolution after COPD diagnosis in the UK primary care setting. PLoS One. 2014;9(9):e105296.

4. Cazzola M, Molimard M. The scientific rationale for combining long-acting beta2-agonists and muscarinic antagonists in COPD. Pulm Pharmacol Ther. 2010;23(4):257-67. 
5. Lipson DA, Barnacle H, Birk R, et al. FULFIL trial: once-daily triple therapy for patients with chronic obstructive pulmonary disease. Am J Respir Crit Care Med. 2017;196(4):438-46.

6. Siler TM, Kerwin E, Tombs L, Fahy WA, Naya I. Triple therapy of umeclidinium + inhaled corticosteroids/long-acting beta2 agonists for patients with COPD: pooled results of randomized placebocontrolled trials. Pulm Ther. 2016;2(1):43-58.

7. Miller MR, Hankinson J, Brusasco V, et al. Standardisation of spirometry. Eur Respir J. 2005;26(2): 319-38.

8. Quanjer PH, Stanojevic S, Cole TJ, et al. Multi-ethnic reference values for spirometry for the 3-95-yr age range: the global lung function 2012 equations. Eur Respir J. 2012;40(6):1324-43.

9. Beeh KM, Derom E, Echave-Sustaeta J, et al. The lung function profile of once-daily tiotropium and olodaterol via $\operatorname{Respimat}{ }^{\circledR}$ is superior to that of twice-daily salmeterol and fluticasone propionate via Accuhaler ${ }^{\circledR}$ (ENERGITO ${ }^{\circledR}$ study). Int J Chron Obstr Pulm Dis. 2016;11:193-205.

10. Sethi S, Kerwin E, Watz H, et al. AMPLIFY: a randomized, phase III study evaluating the efficacy and safety of aclidinium/formoterol vs monocomponents and tiotropium in patients with moderate-tovery severe symptomatic COPD. Int J Chron Obstr Pulm Dis. 2019;14:667-82.

11. Ferguson GT, Brown N, Compton C, et al. Oncedaily single-inhaler versus twice-daily multiple-inhaler triple therapy in patients with COPD: lung function and health status results from two replicate randomized controlled trials. Respir Res. 2020;21(1):131.
12. Boscia JA, Pudi KK, Zvarich MT, Sanford L, Siederer SK, Crim C. Effect of once-daily fluticasone furoate/ vilanterol on 24-hour pulmonary function in patients with chronic obstructive pulmonary disease: a randomized, three-way, incomplete block, crossover study. Clin Ther. 2012;34(8): 1655-1666e5.

13. Cazzola M, Beeh KM, Price D, Roche N. Assessing the clinical value of fast onset and sustained duration of action of long-acting bronchodilators for COPD. Pulm Pharmacol Ther. 2015;31:68-78.

14. Leather DA, Yates L, Svedsater $H$, et al. Can medicines development improve outcomes in asthma and chronic obstructive pulmonary disease management by driving effectiveness? Respir Res. 2019;20(1):173.

15. Cramer JA, Roy A, Burrell A, et al. Medication compliance and persistence: terminology and definitions. Value Health. 2008;11(1):44-7.

16. Bogart M, Stanford RH, Laliberté F, Germain G, Wu JW, Duh MS. Medication adherence and persistence in chronic obstructive pulmonary disease patients receiving triple therapy in a USA commercially insured population. Int $\mathrm{J}$ Chron Obstr Pulm Dis. 2019;14:343-52.

17. Gaduzo S, McGovern V, Roberts J, Scullion JE, Singh D. When to use single-inhaler triple therapy in COPD: a practical approach for primary care health care professionals. Int J Chron Obstr Pulm Dis. 2019;14:391-401.

18. Yu AP, Guérin A, Ponce de Leon D, et al. Therapy persistence and adherence in patients with chronic obstructive pulmonary disease: multiple versus single long-acting maintenance inhalers. J Med Econ. 2011;14(4):486-96. 